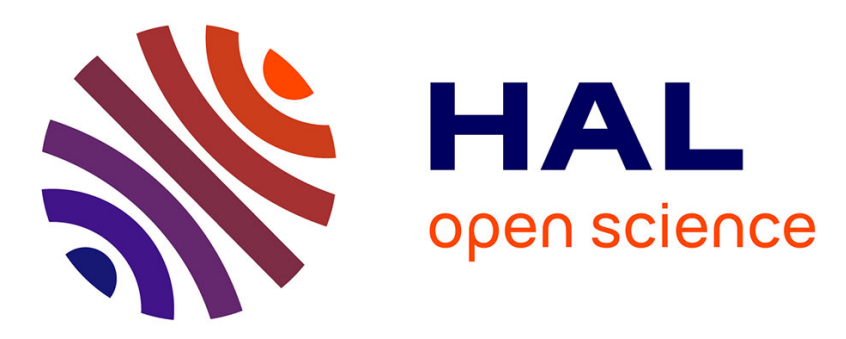

\title{
An Exploration of Opportunities for a Theory of Information Inadequacy
}

Miranda Kajtazi, Darek Haftor

\section{To cite this version:}

Miranda Kajtazi, Darek Haftor. An Exploration of Opportunities for a Theory of Information Inadequacy. 13th IFIP International Conference on Human Choice and Computers (HCC13), Sep 2018, Poznan, Poland. pp.384-394, 10.1007/978-3-319-99605-9_29 . hal-02001926

\section{HAL Id: hal-02001926 \\ https://hal.inria.fr/hal-02001926}

Submitted on 31 Jan 2019

HAL is a multi-disciplinary open access archive for the deposit and dissemination of scientific research documents, whether they are published or not. The documents may come from teaching and research institutions in France or abroad, or from public or private research centers.
L'archive ouverte pluridisciplinaire HAL, est destinée au dépôt et à la diffusion de documents scientifiques de niveau recherche, publiés ou non, émanant des établissements d'enseignement et de recherche français ou étrangers, des laboratoires publics ou privés.

\section{(c)(1)}

Distributed under a Creative Commons Attribution| 4.0 International License 


\title{
An Exploration of Opportunities for a Theory of Information Inadequacy
}

\author{
Miranda Kajtazi ${ }^{1[0000-0003-2445-654 X]}$, Darek Haftor ${ }^{2[0000-0003-0491-2122]}$ \\ ${ }^{1}$ Lund University, 22362 Lund, Sweden \\ miranda.kajtazi@ics.lu.se \\ ${ }^{2}$ Uppsala University, 75120 Uppsala, Sweden \\ darek.haftoreim.uu.se
}

\begin{abstract}
Our everyday experiences show that the lack of needed information in various human affairs may give rise to consequences that we would like to avoid - e.g. the 2004 Tsunami in Southeast Asia. However, we still do not have a coherent theoretical body that addresses such experiences of information inadequacy as this changes everything in respect to the current conception of the information society, where technology plays a central role. To this end, we provide an initial exploration of opportunities for such a theory: when needed information is not available in human affairs, for any reason. We start with diagnoses of five existing central theoretical bodies that constitute promising candidates to account for instances of information inadequacy. The results show though that these do not offer a comprehensive account for situations where needed information is missing. Secondly, an empirical investigation was conducted, utilizing grounded theory approach, where fifty cases of information inadequacy were analysed. This revealed a number of patterns of plausible causes of information inadequacies in human affairs, which offer a preliminary foundation for a future theory of information inadequacy. This result suggests that information inadequacies may be understood as various instances of informationlack and information-overflow. These two, in turn, include numerous factors that cause information inadequacies, ranging from political and cultural structures, through human individual capabilities, and ending with procedural setups and technological artefacts. We advocate that further research should be conducted to explore various instances of information inadequacy aimed to the formulation of a coherent theory.
\end{abstract}

Keywords: Information Management, Information Needs, Information Overload, Information Lack, Information Inadequacy.

\section{Introduction}

Some fundamental questions of our contemporary debates are concerned with phenomena that relate to information problems, predominantly experienced with difficulties in human, social and industrial affairs. Such are the dramatic situations of e.g. the Lehman Brothers bankruptcy in 2008, the tsunami in Indonesia in 2004, the Space Shuttle Challenger destruction in 1986 or the release of the atomic bomb in 1945. 
Situations like these are concerned with decision-making processes and require a rational behavior to process information related to them [17]. Philosophers, scientists and industrialists hypothesize about information problems and intend to develop theories or solutions that are partially helpful [1,2], [8].

Information has a deep impact on personal well-being, decision-making processes, innovation and production [7], [12]. But, the failure to achieve balance between the surging volumes of information we access (mostly affected by electronic information) and its obverse, the information underload [20], allow conceptualizing that the information-related problems are fairly typical. Our everyday experiences manifest numerous instances in which information is the key that generates various consequences, many of which are experienced as failures and fatalities in human, social and industrial affairs. Therefore, in this paper a core phenomenon is explored: the lack of needed information in human, social and industrial affairs. The lack of needed information is understood as a composition of different behavioral aspects of human agents that implicate how the production, the transfer or the use of information is performed based on intrusive manners. Although related topics have tackled similar phenomena for some decades now [6, 7], [12], [18], [20], there is little we understand about it. Indeed, there is no comprehensive understanding that has tackled such a phenomenon at length.

The objective of this paper is to give an understanding of the phenomenon of the lack of needed information by developing a model of why and how the lack of needed information contributes to unwanted consequences in human, social and industrial affairs. Empirically, the exploration of this phenomenon is based on grounded theory approach as originated by Glaser and Strauss [11], but has been further developed by Orlikowski [19], Sarker et al. [22], and Charmaz [5].

The paper is organized as follows. First, a literature review on five information behavior theories is presented. Then, an overview of grounded theory approach is provided. Furthermore, the application of grounded theory approach (coding process) and a model derived from data analysis are presented. Finally, the paper gives some practical and theoretical implications that may advance studies with focus on the lack of needed information and its impact in organizations and societies.

\subsection{Do Information Behavior Theories Account for Information Inadequacy?}

Five theories have been of particular interest to investigate the phenomenon in context, selected during a careful literature search on aspects of information overflow and information lack: Social Network Theory; Social Cognitive Theory; Theory of Information Asymmetry; Information Theory; and Social Construction of Technology Theory. Conceptually, these five theories are examined in terms of their use in developing information behavior theories, which are intended to understand information practices (information need and seeking, information-seeking behavior, cognitive information retrieval, etc.). Information behavior theories are well established and focus on information-related phenomena, which mostly tend to address human cogni- 
tive behavior in relation to using information in its physical or digital form ${ }^{1}$. These theories represent an interdisciplinary approach that refers to various aspects of information behavior, and are therefore thought to be useful in addressing the phenomenon of the lack of needed information. The selection of these five theories is based on the need to investigate their potentials in addressing the phenomenon of the lack of needed information. Selected theories are based on characteristics that profoundly influence problem-solving activities that are specifically focused on trying to understand human motivational states when people are involved in various information practices. Below, a short introduction to each of these theories is given, in order to understand their benefits, limitations and implications for the phenomenon of the lack of needed information.

Social Network Theory was first coined by Barnes [3]. This theory intends to specify the role of an individual in a social group. The use of this theory in information behavior theories is based on the idea that human information behavior is shaped by and shapes individuals, social networks, situations and contexts where information practices take place. This theory is widely used in understanding information needs, information construction, and actions based on available information all focusing on information problems that concern individuals in a social group. In summary, social network theory is mainly used in determining the perception of the need for information in relation to its availability to satisfy the need of an individual. Searching for an understanding of the lack of needed information, the benefit of this particular theory is in its focus on "information need". However, this theory only partially helps to determine the information needs of an individual in dramatic situations, because dramatic situations always happen unexpectedly, and therefore the availability of and the need for information in a particular situation is unexpected when needed for edgy decisions.

Social Cognitive Theory originated from Bandura [2]. This theory is used to develop information behavior theories to show how individuals operate with information based on their cognitive activities. It examines how individuals influence behavior change and developments in social groups, when they are engaged in different forms of social experiences by determining the meaning of information and its exchange in social interactions [25]. This theory is interesting for elaborating on human thought and action in a particular situation. Nevertheless, its limitation for understanding the lack of needed information in dramatic situations is that it only focuses on individual's behavior in information-seeking processes, mostly for their own needs, and not on their needs that are determined by the situation itself.

The Theory of Information Asymmetry was first introduced by Akerlof [1]. This theory is used to explain the role of asymmetric information in economic transactions. It focuses on human behavioral aspects when engaged in economic transaction, specifically focusing on "dishonesty" in economic markets. The theory explains how individuals are prone to influence the inclusion of imperfect information in economic transactions of personal interest [1]. This theory is helpful for understanding how the meaning of information is affected in situations where an individual influences the

1 [10] p.3 xix 
meaning for personal benefit. Yet, in general and in dramatic situations where the meaning of information is rather unexpected and not necessarily influenced by another individual, this theory can only partially account for individuals' needs for a decision making process.

Information Theory has flourished since Shannon's model of a mathematical theory of communication [23]. This theory is mostly used to understand how information messages can be transmitted in a linear engineering form, using two entities: sender and receiver. Information theory was further developed and used to construct new information behavior theories that also focus on human-related information messages. Among its uses in many engineering disciplines, information theory is also used in communication theory to advance the study of information retrieval processes. This theory is steadily advancing, but in practice such advancements still remain entangled in the field of engineering. In dramatic situations it is impractical to use automated processes for information retrieval where information needs cannot be always fulfilled by means of technology. This is because the lack of needed information appears in diverse situations and contexts, where technology may still be inaccessible.

The Social Construction of Technology Theory focuses on the development of technologies influenced by human needs. The most influential scholars that advocate the social construction of technology are Pinch and Bijker [21]. This theory is interesting in that it presents an interplay between social, economic, political and environmental factors in the process of developing technology. Thus, social construction is characterized by the needs of individuals that influence innovation and development of technology to fulfil human needs. The theory then suggests that the phenomenon of the lack of needed information may be manageable in the future as technology develops at a rapid pace, mostly focusing on optimizing information flows for human needs. However, this still remains challenging, considering that in many situations technology is not always helpful for timely provision of information and in uncertain developments of situations.

From the above introduction, it is evident that such theories derive from different disciplines. Their intention is to specify how people need, seek, manage, give and use information in different contexts. This suggests that information behavior theories call for an interdisciplinary approach to investigate the phenomenon of the lack of needed information. This review suggests that although such theories account for the phenomenon of the lack of needed information, their focus is rather implicit and their benefit is only partial in trying to understand and remedy situations where the needed information is lacking. Analytically, what is addressed with these theories is rather the behavior of humans or machines that produce, transfer and receive information, as a chain of events, by not specifying what really happens with the production of information, when it happens and how to make sure that timely information can be produced and transferred to meet the human needs in critical situations.

Communication theory was used from the beginning as a guide to understand the addressed theoretical bodies in terms of three roles: the information sender (source), the information mediator, and the information receiver. The analysis showed that the addressed theoretical bodies are significant for partial understanding of what happens with information at the information receiver (the process of information consump- 
tion), but are weak in accounting for information transfer, and they do not address information production, which is central for understanding the lack of needed information. An illustration of this is given in Figure 1:

\begin{tabular}{|c|c|c|c|}
\hline Information Behaviour Theories & $\begin{array}{l}\text { Sender (Source) } \\
\text { Information Production }\end{array}$ & $\begin{array}{l}\text { Mediator } \\
\text { Information Transfer }\end{array}$ & $\frac{\text { Receiver }}{\text { Information Consumption }}$ \\
\hline - Social Network Theory & ? & ? & 0 \\
\hline - Social Cognitive Theory & $?$ & $?$ & O \\
\hline - Theory of Information Asymmetry & $?$ & $?$ & O \\
\hline - Information Theory & $?$ & $\square$ & O \\
\hline - Social Construction of Technology Theory & $?$ & $\square$ & $?$ \\
\hline
\end{tabular}

Fig. 1. Information behavior theories and their impact on sender(source), mediator and receiver of information.

Implications of this literature review have led to the understanding that the phenomenon of the lack of needed information remains unexplored and requires thorough investigations. Thus, there is no comprehensive a priori theory to be used for the design of an empirical investigation. An empirical investigation of various instances of information inadequacy was therefore conducted and is presented in the following.

\section{Empirical Investigation: A Grounded Theory Approach}

A number of authors have developed theories that postulate how problems with information in human affairs arise in different circumstances [1], [7], [9], [15]. These problems may be caused by different factors, among which are the management factor, the political factor or the ethical factor (e.g. [7], [20]). In practice, information is considered as an invaluable asset of three core competent organizational processes engaged in communication: (a) information production; (b) information exchange; and (c) information recipient [16].

Communication in organizational processes is often followed by unprecedented difficulties that result in failure in successful management of information-related practices [13], [20]. There is substantial relevant research that investigates problems with information mirrored in communication theory with the focus on information practices [4], [7], [18]. Recent investigations, especially those of the last two decades, have documented different information-related problems that occur in an unexpected fashion [18]. Theoreticians and practitioners argue that societal, political and economic movements have become more contagious with information problems than ever predicted [14]. This paper intends to give an understanding of information-related problems by analyzing data derived from dramatic situations (e.g. natural disasters, financial failures, etc.) and by systematically applying grounded theory approach in 
order to find an answer that explains how the phenomenon of the lack of needed information arises in human, social and industrial affairs.

\subsection{A Summary of Selected Empirical Cases}

In this study, data collection and analysis are based on secondary sources. The collection resulted in fifty empirical cases. The data analysis is conducted using open coding, axial coding and selective coding, which are adapted for the purpose of this research, according to procedural aspects illustrated by Strauss and Corbin [24], enhanced by Orlikowski [19], Sarker et al. [22] and Charmaz [5].

Fifty empirical cases comprise of different dramatic situations that are selected for the purpose of emphasizing the phenomenon of the lack of needed information. More concretely, the selected number of situations are grouped as follows: Natural Disasters (9); Environmental Disasters (6); Financial Failures (7); Health Failures (6); Political Scandals (6); Conflict Situations (3); Engineering and Technological Failures (8); Nuclear and Chemical Disasters (5). The fifty cases identified are analyzed further on with grounded theory approach. They are categorized in an a priori manner, solely for the purpose of facilitating the reader's understanding of what situations are taken into consideration.

However, this does not have any influence on the empirical analysis.

\section{Data Analysis and Results}

Data analysis emerged iteratively, starting with early open-ended research, primarily line-by-line text analysis, and continued with more strategic selection of emerging concepts and categories [19]. The benefit of the iterative processes is that the initial phase of exploration followed a flexible path in understanding and collecting data, while the later phase of conceptualization followed a more strictly organized path with strategic planning of analysis.

The coding process as formulated by grounded theory approach is employed more formally in data analysis after all the data have been collected, selected and refined. The analyses were based on three types of coding presented by Strauss and Corbin [24], which are: open coding, axial coding, and selective coding.

The initial result of open coding analysis followed with 182 codes. Each code was associated with the representative text as derived from the description of each case. The codes that emerged were needed to give an initial and an informal understanding of what causes the phenomenon of the lack of needed information in human, social and industrial affairs.

The actual conceptualization and interpretation of the phenomenon of the lack of needed information became clear in the early phase of data analysis. The conceptualization of fifty cases developed on the basis of analyzing each case deriving characteristics that could show what causes the lack of needed information. The results of such a conceptualization were mainly dependent on several induced codes that were identified as recurring in many situations. For instance, codes such as "did not alert" or 
"warning system(s)" were crucial for interpreting the phenomenon in context. The use of the majority of codes clearly presented significant similarities in all the situations, resulting in an early, yet a crucial interpretation of the phenomenon in context.

Axial coding continued with constant comparative analysis through data. Codes found in the data became more meaningful when they continued to be merged, changed, and even eliminated. The codes that were merged represented a type of code used to show a key input for the purpose of generating categories. The codes that were changed were adapted to other similar codes, which may have reduced redundancy. The eliminated codes were primarily redundant (it is important to point that the categorization is not only interpretive but also the data spoke for the categorization itself). With axial coding, the analysis process led, firstly, to refining of the identified codes and induction of concepts. Of 182 initial codes, 35 codes were engaged intensively by formulating one group of concepts (17) and two groups of codes: substantive codes (13) and theoretical codes (5). The concepts (17) were successfully used for categorization. The theoretical codes (5) were successfully used for presenting the main causes that justified the identification of (13) substantive codes. Furthermore, the concepts (17) were used to interlink the theoretical codes and substantive codes by showing strong dependency. Detailed overview of these results is presented in Figure 2.

The axial coding analysis that acted based on classifications and comparative analysis resulted in the identification of 8 sub-categories. As a result, the comparative analysis showed two main differences between the 8 identified sub-categories. The differences resulted in grouping the sub-categories by introducing two main axial categories, i.e. information lack and information overflow, and their interrelations with sub-categories, concepts and codes. Therefore, the classification of 35 codes (17 concepts, 13 substantive codes and 5 theoretical codes) into 8 sub-categories and grouped in two main categories is based on the following definitions:

\section{Information Lack}

(1) Information is non-existent. - is characterized by failure to communicate information in situations when actions are unforeseen and the responsible body for transmitting information is unaware of such a need, usually due to mismanagement.

(2) Information is insufficient. - is characterized by failure to communicate ontime information as a result of pre-planning of circumstances that may cause unwanted results in a specific situation. Unawareness, mismanagement and difficulty in understanding represent failure to act in a timely fashion.

(3) Information is censored. - is characterized by serious violation of information. Such information is usually hindered intentionally, secretly and illegally for the purpose of suppressing original information that is intended for the public and that may be significant for their needs. Fraud is one of the key acts that reflect the censoring of information.

(4) Information is undelivered. - is characterized by incompetent acts of humans, with a dual outcome. The act is either done intentionally by prohibiting the use of information or the undelivered information is caused by unawareness. 


\section{Information Overflow}

(5) Information is ambiguous. - is characterized by lack of control of information. It is usually accompanied by miscalculations and lack of accurate evidence that misleads important decision-making processes.

(6) Information is redundant. - is characterized by duplication or even multiplication of the same information (repetition of information's message in synonyms or with the same excessive expression) due to lack of control or unawareness.

(7) Information is irrelevant. - is characterized by types of information that have no validity and are shared by unknown sources. Such information holds misinterpretations.

(8) Information is undervalued. - is characterized by mismanagement that may cause misinterpretation of information, possibly by lack of awareness or unawareness.

A significant number of codes, both substantive and theoretical, that are ultimately used in generating the 8 sub-categories have been recurrent within one or more of the sub-categories, as presented in Figure 2.

Selective coding is employed as the final step required to generate the core category, ultimately to generate a middle-range theory [5]. The data analysis has developed the core category by verifying that the phenomenon of the lack of needed information is evident in practical senses. Thus, the core category as a result of analysis is named in this study "information inadequacy". With the core category at hand, the aim is to integrate all analysis into one formulated comprehensive outline that could portray the phenomenon of the lack of needed information in human, social and industrial affairs.

The analysis performed generated new and interesting results that are used to formulate an explicit meaning of what is characterized as "information inadequacy", defined as follows: "dramatic situations (many of which happen on a daily basis) that encounter information as the key resource in different situations and circumstances, manifest various consequences, many of which are experienced as failures and fatalities in human, social and industrial affairs". 


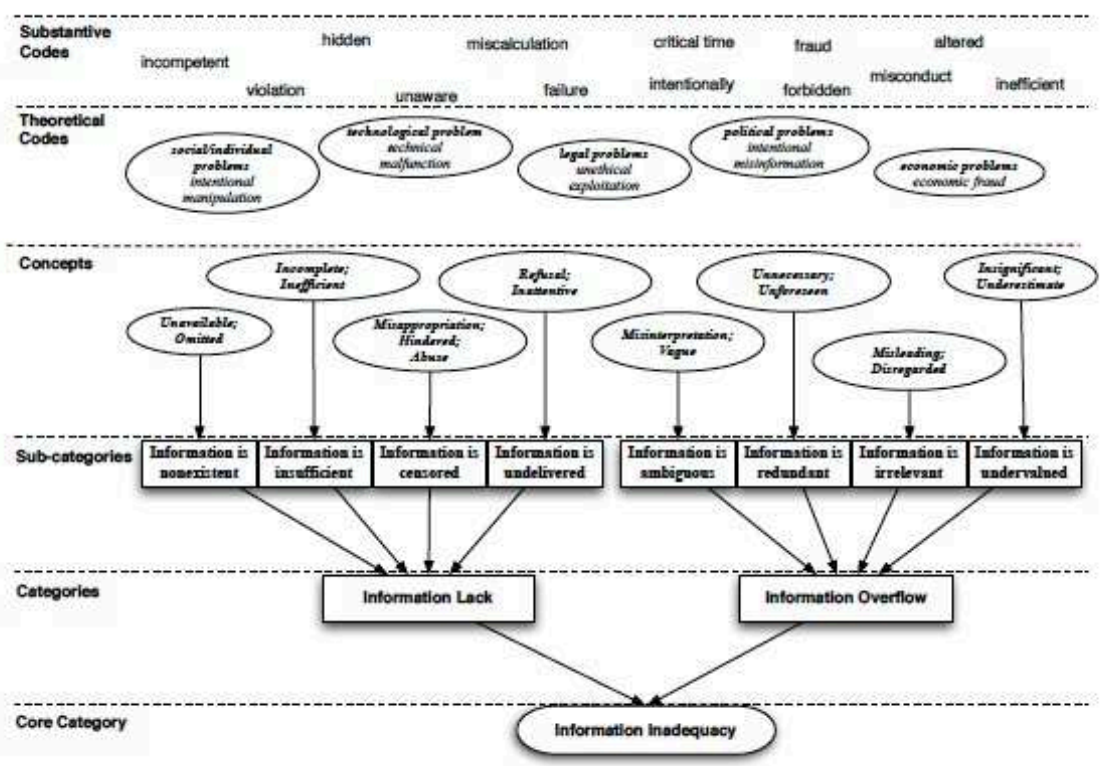

Fig. 2. Information behavior theories and their impact on sender(source), mediator and receiver of information.

It is justifiable, as well as moderate, to state that information inadequacy as such is not taken as seriously as a problem in our current information society, which is usually accompanied by unwanted consequences.

\section{Conclusion}

This study has proposed an initial outline of information inadequacy that resulted from the need to understand the phenomenon of the lack of needed information.

The theoretical investigation was initiated with the need to identify theoretical bodies that may clarify what causes this phenomenon. This study found that theoretical bodies that implicitly claim to handle this phenomenon, i.e. Information Behavior Theories, cannot account for, explain, or suggest a remedy for the dramatic situations where there is a lack of needed information. These can only account for a partial, hence, a limited understanding of the phenomenon in context.

A need for empirical investigations thus became crucial, and it triggered new explorations in interpreting what is changing about today's information access and what remains critical in global information landscapes (these may vary from social, political, economic or environmental landscapes). The empirical investigation was based on a constructivist grounded theory approach on a collection of fifty empirical cases. This investigation resulted in the identification of characteristics, patterns and causes of how the needed information fails to reach the intended person at the right time and place, causing unwanted consequences. The analysis suggested that information- 
related problems of that nature mainly appear because of problems that are caused by information source (sender) and information mediator - human or machine. The results of this investigation have developed an initial outline of information inadequacy that could possibly guide the development of a future theory of information inadequacy.

In practice, the proposed outline of information inadequacy addresses all humans who are concerned with information in everyday practices and intend to enhance their time by carefully managing information. More importantly, information inadequacy can be a diagnosis tool that allows industrialists, technology developers, environmentalists and others to think for enhancing information communication in the future.

Given the results of the empirical investigation conducted here, the identified factors portray how hindrances to information provision may be utilized as guidelines for the diagnosis and re-design of information provision processes. In short, this would imply that each pattern of information inadequacy identified, might be used to direct new and innovative diagnostic and re-design teams that focus on information management and on more careful planning of information flows that are present and important in dramatic situations that happen in everyday basis. Such an understanding may possibly guide further development of a future theory of information inadequacy that can be instrumental in developing more efficient information systems for organizations and societies for an operational use of information.

\section{References}

1. Akerlof, G.: The market for 'Lemons': quality uncertainty and the market mechanism. Quarterly Journal of Economics 84(3), 488-500 (1970).

2. Bandura, A.: Self-efficacy: toward a unifying theory of behavioral change. Psychological Review 84(2), 191-215 (1977).

3. Barnes, J.A.: Class and committees in a Norwegian island parish. Human Relations 7, 3958 (1954).

4. Bawden, D., Robinson, L.: Training for information literacy: diverse approaches. In: Proceedings of the International Online Information Meeting, pp. 87-90. Learned Information Europe Ltd, Oxford (2001).

5. Charmaz, K.: Constructing grounded theory: a practical guide through qualitative analysis. Sage Publications, Thousand Oaks (2006).

6. Creese, G.: Information scarcity to information overload. Information Management Magazine Jan, 20-22 (2007).

7. Dean, D., Webb, C.: Recovering from information overload. McKinsey Quarterly (2011). https://www.mckinseyquarterly.com/Recovering_from_information_overload_273, last accessed 2018/04/25

8. Ennals, R., Stratton, L., Moujahid, N., Kovela, S.: Global information technology and global citizenship education. AI \& Society, 23, 61-68 (2009).

9. Eppler, M. J., Mengis, J.: The concept of information overload: a review of literature from organization science, Accounting, Marketing, MIS, and Related Disciplines. The Information Society 20, 325-344 (2004). 
10. Fisher, E. K., Erdelez, S., McKechnie, L.: Theories of information behavior. 2nd edn. American Society for Information Science and Technology, New Jersey (2006).

11. Glaser, B., Strauss, A. L.: (1967). The discovery of grounded theory: strategies for qualitative research. Aldine, Chicago (1967).

12. Hemp, P.: Death by information overload. Harvard Business Review (2009). http://hbr.org/2009/09/death-by-information-overload/ar/1, last accessed 2018/04/25

13. Hwang, M. I., Lin, J. W.: Information dimension, information overload and decision quality. Journal of Information Science 25(3), 213-219 (1999).

14. Krotoski, A. (2010). The information revolution. Undergraduate Lecture Series. Oxford Internet Institute (), http://alekskrotoski.com/post/oxford-internet-institute-theinformationrevolution, last accessed 2018/04/25

15. Mingers, J. C.: Information and meaning: foundations for an intersubjective account. Information Systems Journal 5(4), 285-306 (1995).

16. Mortensen, C. D.: Communication theory. 2nd edn. Transaction Publishers, New Jersey (2009).

17. Newell, A., Simon, H. A.: Human problem solving. Prentice-Hall, Englewood Cliffs (1972).

18. Ojala, M.: Transforming information quality, Online 33(4), N/A (2009).

19. Orlikowski, W. J.: CASE tools as organizational change: investigating incremental and radical changes in systems development. MIS Quarterly 17(3), 309-340 (1993).

20. O'Reilly, Ch. A.: Individuals and information overload in organizations: is more necessarily better? The Academy of Management Journal 23(4), 684-696 (1980).

21. Pinch, T. J., Bijker, W. E.: Science, relativism and the new sociology of technology: reply to Russell. Social Studies of Science 16(May), 347-360 (1986).

22. Sarker, S., Lau, F., Sahay, S.: Using an adapted grounded theory approach for inductive theory building about virtual team development. The database for Advances in Information Systems 32(1), 38-56 (2001).

23. Shannon, C. E. A.: Mathematical theory of communication. Bell Systems Technical Journal 27, 379-423 (1948).

24. Strauss, A., Corbin, J.: Basics of qualitative research. Newbury Park, Sage Publications, California (1990).

25. Wilson, T.: Information-seeking behaviour: designing information systems to meet our client's needs. In: 25th International Conference of the Association of Caribbean University, Research and Institutional Libraries, San Juan (1995). 